\title{
Estimating removals of contaminants of emerging concern from wastewater treatment plants: The critical role of wastewater hydrodynamics
}

\author{
Zeina Baalbaki $^{\mathrm{a}}$, Tamanna Sultana ${ }^{\mathrm{b}}$, Chris Metcalfe $^{\mathrm{b}}$, Viviane Yargeau ${ }^{\mathrm{a},{ }^{*}}$ \\ a Department of Chemical Engineering, McGill University, 3610 University St., Montreal, QC, H3A 0C5, Canada \\ ${ }^{\mathrm{b}}$ Water Quality Centre, Trent University, 1600 West Bank Drive Peterborough, ON, K9J 7B8, Canada \\ *Corresponding author. Tel.:+1 514398 2273; fax: +1 514398 6678; E-mail address: viviane.yargeau@mcgill.ca (V. Yargeau).
}

\begin{abstract}
Accurate data are needed to evaluate the capacity of wastewater treatments plants (WWTPs) to remove contaminants of emerging concern (CECs). The variability of CEC removals reported in the literature has raised questions about the methods used to estimate removals. In this study, we used the recently proposed "fractionated approach" to account for the influence of hydrodynamics in WWTPs and applied this method for estimating removals of 23 target CECs. Data on the conductivity and temperature of wastewater at two WWTPs were used to determine the hydraulic model that best described the flow regime of treatment units. Composite samples (24-h) were collected at different stages of treatment over successive days. The concentrations of the target compounds in wastewater were determined by liquid chromatography with mass spectrometry. Different hydraulic models were necessary to define the hydrodynamics at the two WWTPs, resulting in different load fractions to be used in calculations of removals. For WWTP A, that has a primary clarifier, all target CECs, except triclosan, were poorly removed during this step at efficiencies $<30 \%$. On the other hand, the activated sludge treatment unit at both WWTPs removed most target CECs at $>70 \%$. This study expanded the application of the fractionated approach to compare the hydraulics of two treatment trains of different configurations, including primary and secondary treatment. It demonstrated the sensitivity of the method to account for variations between the different treatment units. Reliable removals of an extended list of CECs in primary and secondary treatment were also provided in this study.
\end{abstract}

Keywords: Micropollutants, Fractionated approach, Hydraulic model, Removal efficiency, Activated sludge, Primary clarification 


\section{Introduction:}

Contaminants of emerging concern (CECs), which include pharmaceuticals and personal care products (PPCPs), drugs of abuse and steroid hormones have been detected globally in the aquatic environment. The sources of these CECs are industrial and domestic wastewater, including hospital effluents (Luo et al., 2014). There is evidence that discharges of CECs into surface waters may have adverse effects on aquatic organisms (Gay et al., 2016; Kidd et al., 2007; Purdom et al., 1994). In addition, CECs may contaminate sources of drinking water (Kleywegt et al., 2011; Metcalfe et al., 2014; Rodayan et al., 2015), although it is not clear whether the low concentrations typically detected in drinking water are a threat to human health (Schwab et al., 2005; Webb et al., 2003).

Municipal wastewater treatment plants (WWTPs) are not designed to remove micropollutants, and many CECs are not removed effectively during treatment (Luo et al., 2014; Onesios et al., 2009; Verlicchi et al., 2012). Most WWTPs in North America treat sewage using secondary treatment technologies, after which wastewater is discharged to the aquatic environment, sometimes without a disinfection step prior to discharge. Removals of CECs reported in literature vary significantly for given compounds, even for WWTPs with comparable treatment processes, which raises questions about the reliability of the data. Ort et al. (2010) reviewed the available data on removals of CECs in WWTPs and concluded that the sampling schemes typically used are inadequate for accurately estimating these removals. "Negative" removals, or concentrations of CECs in final treated effluents that are higher than concentrations in untreated influent are frequently observed, especially for recalcitrant compounds, such as carbamazepine (Yang et al., 2011; Zorita et al., 2009). Some of these negative removals have been attributed to de-conjugation of Phase II metabolites during biological treatment, resulting in generation of the unconjugated parent compound (Ternes, 1998), as well as to desorption from sludge and particulate matter during treatment (Clara et al., 2005; Ternes, 1998).

The negative and variable removals of CECs estimated for WWTPs may be due to sampling schemes that do not account for the fact that the daily incoming load is distributed over multiple days in the effluent due to the residence time distribution (RTD) of wastewater. Majewsky et al. (2011) recommended an approach to sampling and removal calculations 
within WWTPs, described as the "the fractionated approach", that compares the mass load of the output stream with a reference mass load of the input stream that takes into account the RTD. This approach requires a more intensive sampling strategy over several days, together with hydraulic modelling of the WWTP, utilizing conductivity as a tracer of the RTD (Majewsky et al., 2011). Ahnert et al. (2010) proposed that also temperature could be used as a tracer to determine the RTD within WWTPs. A subsequent study by Majewsky et al. (2013) using the fractionated approach generated superior estimates of the removals of five pharmaceuticals and four pesticides in a WWTP with activated sludge treatment.

Our subsequent application of the fractionation approach for the removal of drugs of abuse in an activated sludge unit of a WWTP demonstrated the value of this method over conventional approaches for removal calculations (Rodayan et al., 2014a). As a further advance over our previous study, the goal of the present study was to evaluate the capacity of the fractionated approach to estimate CEC removals from the aqueous phase in two WWTPs with different treatment configurations and RTDs. The treatment processes monitored at the two WWTPs were the activated sludge units, as well as a primary clarifier at one of the WWTPs. We applied this method to obtain reliable estimates of removals of 23 target CECs that have been widely detected in domestic wastewater, including several drugs of abuse and pharmaceuticals, two steroid hormones (i.e. estrone, androstenedione), a stimulant (i.e. caffeine), an artificial sweetener (i.e. sucralose) and an antibacterial compound found in personal care products (i.e. triclosan). Wastewater samples were analyzed for CECs using liquid chromatography with high-resolution mass spectrometry (LC-HRMS) and liquid chromatography with tandem mass spectrometry (LC-MS/MS).

\section{Materials and Methods:}

\subsection{CECs, chemicals and reagents}

Several of the target compounds in this project were selected according to the criteria identified by Dickenson et al. (2011) in a study that illustrated the value of monitoring a small number of CECs in wastewater treatment facilities in the U.S. Sucralose has been widely detected in drinking water systems in the USA and because of its persistence and ubiquitous presence at high concentrations, has been proposed as a tracer of wastewater contamination (Mawhinney et al., 2011). Our previous studies have shown that drugs of 
abuse, including cocaine and its major metabolite (i.e. benzoylecgonine), amphetamines and opioid drugs are widely distributed in wastewater in Canada (Metcalfe et al., 2010; Rodayan et al., 2015). For methadone and cocaine, the fate of the metabolites (i.e. EEDP and benzoylecgonine, respectively) was also taken into account. The target CECs selected for monitoring in the two WWTPs are listed in Table 1.

Table 1 Target compounds and their physicochemical properties, internal standards, LODs \& LOQs and class for extraction and analysis.

\begin{tabular}{|c|c|c|c|c|c|c|c|c|c|}
\hline Type and Subtype & Compound & CAS No & $\begin{array}{l}\text { Molecular } \\
\text { Formula }\end{array}$ & $\begin{array}{l}\text { Molecular } \\
\text { Weight }\end{array}$ & $\mathrm{pKa}^{\mathrm{a}, \mathrm{b}}$ & $\begin{array}{l}\text { Log } \\
\text { Kow }^{\text {a,b }}\end{array}$ & Class & Internal Standard & $\begin{array}{l}\text { LOD, LOQ } \\
(\mathrm{ng} / \mathrm{L})\end{array}$ \\
\hline \multirow[t]{2}{*}{ Antibiotics } & Trimethoprim & $738-70-5$ & $\begin{array}{l}\mathrm{C}_{10} \mathrm{H}_{11} \mathrm{~N}_{3} \mathrm{O}_{3} \\
\mathrm{~S}\end{array}$ & 290.3 & 6.8 & 0.91 & B & Trimethoprim-13C3 & 7,22 \\
\hline & Sulfamethoxazole & $723-46-6$ & $\mathrm{C}_{14} \mathrm{H}_{18} \mathrm{~N}_{4} \mathrm{O}_{3}$ & 253.3 & 5.7 & 0.89 & B & Sulfamethoxazole-13C6 & 4,14 \\
\hline Anti- & Acetaminophen & $103-90-2$ & $\mathrm{C}_{8} \mathrm{H}_{9} \mathrm{NO}_{2}$ & 151.2 & 9.0 & 0.46 & B & Acetaminophen -D3 & 11,35 \\
\hline inflammatory/analge & Codeine & $76-57-3$ & $\mathrm{C}_{18} \mathrm{H}_{21} \mathrm{NO}_{3}$ & 299.4 & 8.2 & $1.14^{\mathrm{a}}$ & A & Codeine-D3 & 8,28 \\
\hline \multirow[t]{2}{*}{ sics } & Ibuprofen & $15687-27-1$ & $\mathrm{C}_{13} \mathrm{H}_{18} \mathrm{O}_{2}$ & 206.2 & 4.9 & 3.97 & B & Ibuprofen-13C3 & 6,21 \\
\hline & Naproxen & $22204-53-1$ & $\mathrm{C}_{14} \mathrm{H}_{14} \mathrm{O}_{3}$ & 230.3 & 4.2 & 3.18 & B & naproxen-13c1-d3 & 4,14 \\
\hline Antiepileptic & Carbamazepine & $298-46-4$ & $\mathrm{C}_{15} \mathrm{H}_{12} \mathrm{~N}_{2} \mathrm{O}$ & 263.3 & 3.2 & 2.45 & B & Carbamazepine-D10 & 2,5 \\
\hline $\begin{array}{l}\text { Antilipidemic (lipid } \\
\text { regulator) }\end{array}$ & Gemfibrozil & $25812-30-0$ & $\mathrm{C}_{15} \mathrm{H}_{22} \mathrm{O}_{3}$ & 250.3 & 4.7 & 4.77 & $\mathrm{~B}$ & Gemfibrozil-D6 & 5,16 \\
\hline Dopamine uptake & Cocaine & $50-36-2$ & $\mathrm{C}_{17} \mathrm{H}_{21} \mathrm{NO}_{4}$ & 303.4 & 8.6 & 2.3 & $A$ & Cocaine-D3 & 38,126 \\
\hline $\begin{array}{l}\text { inhibitor (cocaine } \\
\text { and its metabolite }\end{array}$ & $\begin{array}{l}\text { Benzoylecgonine } \\
\text { (cocaine metabolite) }\end{array}$ & $519-09-5$ & $\mathrm{C}_{16} \mathrm{H}_{19} \mathrm{NO}_{4}$ & 289.3 & NA & -1.32 & $A$ & Benzoylecgonine-D3 & 6,21 \\
\hline and amphetamine- & Amphetamine & $300-62-9$ & $\mathrm{C}_{9} \mathrm{H}_{13} \mathrm{~N}$ & 135.2 & 10.1 & 1.76 & $A$ & Amphetamine-D5 & 6,28 \\
\hline \multirow[t]{2}{*}{ type stimulants) } & Ephedrine & $299-42-3$ & $\mathrm{C}_{10} \mathrm{H}_{15} \mathrm{NO}$ & 165.2 & 9.7 & 1.13 & A & Ephedrine-D3 & 11,37 \\
\hline & MDA & $4764-17-4$ & $\mathrm{C}_{10} \mathrm{H}_{13} \mathrm{NO}_{2}$ & 179.2 & 9.7 & 1.64 & A & MDA-D5 & 12,41 \\
\hline \multirow[t]{5}{*}{ Opioids } & Dihydrocodeine & $125-28-0$ & $\mathrm{C}_{18} \mathrm{H}_{23} \mathrm{NO}_{3}$ & 301.4 & 8.8 & $1.49^{c}$ & A & Dihydrocodeine-D6 & 12,41 \\
\hline & Methadone & $76-99-3$ & $\mathrm{C}_{21} \mathrm{H}_{27} \mathrm{NO}$ & 309.4 & 8.9 & 3.93 & A & Methadone-D9 & 6,20 \\
\hline & $\begin{array}{l}\text { EDDP (methadone's } \\
\text { metabolite) }\end{array}$ & $30223-73-5$ & $\mathrm{C}_{20} \mathrm{H}_{23} \mathrm{~N}$ & 291.4 & 9.6 & 4.94 & $A$ & EDDP-D3 & 8,26 \\
\hline & Morphine & $57-27-2$ & $\mathrm{C}_{17} \mathrm{H}_{19} \mathrm{NO}_{3}$ & 285.3 & 9.9 & 0.96 & A & Morphine-D3 & 7,25 \\
\hline & Tramadol & $27203-92-5$ & $\mathrm{C}_{16} \mathrm{H}_{25} \mathrm{NO}_{2}$ & 263.4 & 9.4 & 2.63 & A & Tramadol-13C-D3 & 11,36 \\
\hline $\begin{array}{l}\text { Disinfectants/antise } \\
\text { ptics }\end{array}$ & Triclosan & $3380-34-5$ & $\mathrm{C}_{12} \mathrm{H}_{7} \mathrm{Cl}_{3} \mathrm{O}_{2}$ & 289.6 & 7.9 & 4.76 & B & Triclosan-13C12 & 6,19 \\
\hline \multirow[t]{2}{*}{ Steroid hormones } & Androstenedione & $63-05-8$ & $\mathrm{C}_{19} \mathrm{H}_{26} \mathrm{O}_{2}$ & 286.4 & $N A^{e}$ & 2.75 & B & $\begin{array}{l}\text { Androstene-3,17-dione- } \\
2,3,4-13 \mathrm{C} 3\end{array}$ & 2,5 \\
\hline & Estrone & $53-16-7$ & $\mathrm{C}_{18} \mathrm{H}_{22} \mathrm{O}_{2}$ & 270.4 & 10.3 & 3.13 & B & Estrone-3,4-13C2 & 2,5 \\
\hline Stimulant & Caffeine & $58-08-2$ & $\mathrm{C}_{8} \mathrm{H}_{10} \mathrm{~N}_{4} \mathrm{O}_{2}$ & 194.2 & 14.0 & -0.07 & B & Caffeine-13C3 & 4,14 \\
\hline Artificial sweetener & Sucralose & $56038-13-2$ & $\mathrm{C}_{12} \mathrm{H}_{19} \mathrm{Cl}_{3} \mathrm{O}_{8}$ & 397.6 & $\mathrm{NA}^{\mathrm{e}}$ & $-1^{d}$ & B & Sucralose-D6 & 7,22 \\
\hline
\end{tabular}

${ }^{a}$ The PubChem Project National Center for Biotechnology Information (2004)

${ }^{\text {b }}$ Ratola et al. (2012)

${ }^{c}$ ChemIDPLUS U.S. National Library of Medicine (2005)

${ }^{\mathrm{C}}$ Subedi and Kannan (2014a)

${ }^{e} \mathrm{NA}$ : not available 
The target CECs are grouped into two classes according to their chemical properties and the methods of extraction and analysis. Class A compounds are drugs of abuse and their metabolites, which are all weak bases, and Class B compounds are all other analytes, which are either weak acids, phenolics or neutral compounds. Class A compounds and their deuterated stable isotope surrogates were purchased from Cerilliant (Round Rock, TX, USA). PPCPs and steroids from the Class B group were purchased from Sigma-Aldrich Canada (Oakville, ON, Canada) and their stable isotope surrogates were purchased from $\mathrm{C} / \mathrm{D} / \mathrm{N}$ Isotopes (Pointe- Claire, QC, Canada), except for androstenedione, for which a deuterated surrogate was provided by Cerilliant. All standards and stock solutions were stored in amber glass vials at $-20^{\circ} \mathrm{C}$. Methanol, acetonitrile, acetone, formic acid, ammonium hydroxide and sulphuric acid were purchased from Fisher Scientific (Ottawa, ON, Canada). Ultrapure water was generated using a Milli-Q water purification system from Millipore (Bedford, MA, USA).

\subsection{WWTPs characteristics}

Two WWTPs that both utilize activated sludge (secondary) treatment, but with different treatment trains were selected for this study. WWTP A, which has a design capacity of $68,200 \mathrm{~m}^{3} / \mathrm{d}$, receives wastewater that is primarily domestic at an average flow of 43,146 $\mathrm{m}^{3} / \mathrm{d}$. This WWTP serves a population of 78,700. The treatment train includes aerated grit tanks, primary clarifiers, and two activated sludge trains, each of which contains two threepass integrated-film activated sludge (IFAS) bioreactors and two secondary clarifiers. WWTP A employs UV for disinfection, after which the effluent is discharged to a nearby river. Table S1 summarizes the main characteristics of these WWTPs, including the solids retention time (SRT), hydraulic retention time (HRT), and the temperature conditions during sampling.

WWTP B, which has a design capacity of $105,000 \mathrm{~m}^{3} / \mathrm{d}$, receives an average wastewater flow of $50,200 \mathrm{~m}^{3} / \mathrm{d}$ and serves a population of 54,000 . The influent flow is composed of $26 \%$ industrial wastewater, with the remaining amount being domestic wastewater. Unlike WWTP A, this plant contains no primary clarifier and the raw sewage undergoes preliminary treatment by screens, followed by activated sludge treatment. The activated sludge treatment comprises four step-feed aeration tanks followed by four secondary clarifiers, and the effluent is discharged into a nearby river without disinfection. 


\subsection{Hydraulic model}

\subsubsection{Electro-conductivity and temperature measurements}

The electrical conductivity and temperature of the wastewater were monitored with HOBO conductivity loggers (Hoskin Scientific, St-Laurent, QC, Canada), which were deployed to take high-frequency measurements (every five minutes). At WWTP A, the probes were deployed at the exit of the grit removal, primary clarifier, aeration tank and secondary clarifier points over two weeks prior to the sampling campaign. For WWTP B, the probes were deployed at the exit of screens, aeration tank and secondary clarifier points in the treatment train over four days, as an earlier calibration of the plant was available. A universal optic-USB base station and Onset HOBOware Pro Version 3.2.2 software (Hoskin Scientific, St-Laurent, QC, Canada) were used for transferring and reading the data, respectively. Conductivity was utilized as a tracer for the investigation of the residence time distribution in WWTP A. However, due to several outliers in the conductivity data for WWTP B, temperature was used as the tracer for residence time in that plant.

\subsubsection{Hydraulic model calibration and load fractions}

WEST modelling and simulation software (Mike Powered by DHI, Hørsholm, Denmark) was used to determine the hydraulic model that best describes the mixing regimes of the treatment units of the two WWTPs, as described by Majewsky et al. (2011). Briefly, the hydraulic model was built using the actual flow conditions and volumes obtained from the WWTP operators, in addition to the actual conductivity (i.e. for WWTP A) and temperature (i.e. for WWTP B) profiles as input. Calibration of each treatment unit was performed by varying the number of aeration tanks in series and the feed layer of the clarifiers. The best-fit hydraulic model was defined to be the model that minimizes the root mean square error (RMSE) between measured and simulated output profiles. Model simulations were run using the bestfit hydraulic model with a 24-h step input of the soluble inert component available in WEST, along with the actual flow rates to represent a hypothetical CEC affected by hydraulics only (i.e. inert). The output of the model was used to determine the load fractions, represented as $f_{i}$, that best describe the output CEC load exiting the treatment unit on a given day (i.e. day i)

as fractions of the incoming loads entering on each of the previous days assuming there is no biodegradation, as described by Majewsky et al. (2011). 


\subsection{Wastewater sampling}

Since obtaining an hourly resolution of the CEC removals is not crucial for the present study, 24-h composite samples were collected in both the influent and the effluent simultaneously over multiple days. Collecting effluent samples over multiple consecutive days eliminates the need for shifting the effluent sampling by an optimum offset after the beginning of the influent sampling. The hydraulic models selected for the two WWTPs under study indicated that in order to measure most of the influent load material that exits on a single day in the effluent, sampling periods of three and four consecutive days are required at WWTP A \& WWTP B, respectively. The explanation for this approach will be described further in the results section. Samples (24-h composite) were collected from the WWTP A at the exit of the grit removal, primary clarifier, aeration tank and secondary clarifier points in the treatment train on September 10-12, 2013. For WWTP B, samples were collected at the exit of screens, aeration tank and secondary clarifier points in the treatment train on September 23-27, 2013. Dry weather conditions prevailed during both sampling periods. The 24-h composite samples were collected using ISCO 6712 samplers (Avensys, St-Laurent, QC, Canada) equipped with 24 collection bottles and packed with ice. These samplers were programmed to collect equalvolume time-proportional samples every 15 minutes. Samples were then placed in 1-L amber HDPE bottles (Fisher Scientific, Ottawa, ON, Canada) and stored at $-20^{\circ} \mathrm{C}$ until extracted.

\subsection{Sample preparation}

Prior to extraction, wastewater samples were filtered using 1- $\mu \mathrm{m}$ glass-fiber filter (Fisher Scientific, Ottawa, ON, Canada). All compounds were extracted using solid phase extraction (SPE) techniques using Oasis cartridges purchased from Waters (Milford, MA, USA). Sample volumes extracted were $100 \mathrm{~mL}$ for untreated wastewater influent and $200 \mathrm{~mL}$ for all other wastewater samples. The extraction method for Class A compounds was described by Metcalfe et al. (2010) and modified by Yargeau et al. (2014). For Class B compounds, the extraction method was previously described by Li et al. (2010) and Metcalfe et al. (2014). Table S2 summarizes the methods and the instruments used for extracting the two classes of compounds. Prior to extraction, samples were spiked with $100 \mu \mathrm{L}$ of $500 \mathrm{ng} / \mathrm{mL}$ of the stable isotope internal standards listed in Table 1. Recoveries of Class A compounds by the SPE procedure were in the range of $55 \%$ to $110 \%$, while for Class B compounds, SPE recoveries ranged from $71 \%$ to $130 \%$, as reported by Li et al. (2010). 


\subsection{Analysis}

Analysis of the Class A compounds was conducted by LC-HRMS using an Accela LC system coupled to a LTQ Orbitrap XL (Thermo Fisher Scientific, Waltham, MA, USA). Chromatographic separation was achieved using the method described by (Rodayan et al., 2014b). Ionization was operated using heated electrospray ionization source (HESI) in positive mode using the method described in (Rodayan et al., 2014a). Acquisition was performed in full scan mode $(50-400 \mathrm{~m} / \mathrm{z})$ at high resolution $(\mathrm{RFWHM}=41,000)$. The ions of interest were extracted using an $\mathrm{m} / \mathrm{z}$ window of \pm 0.01 .

Class B compounds were analyzed by LC-MS/MS using an Agilent 1100 HPLC (Mississauga, ON, Canada) coupled to a Q-Trap 5500 instrument (AB Sciex, Concord, ON, Canada) with a turbo spray ionization source. The chromatographic method was previously described by Metcalfe et al. (2014). Acquisition was performed using the precursor and product ion transitions for multiple reaction monitoring (MRM) of the target analytes and their corresponding deuterated surrogates. The MRM transitions for the target compounds are also listed in the same study (Metcalfe et al., 2014). Negative ionization mode was used for the analysis of sucralose, ibuprofen, gemfibrozil, estrone, naproxen, and triclosan, whereas, positive ionization mode was used for carbamazepine, sulfamethoxazole, androstenedione, acetaminophen and caffeine.

A linear calibration curve of seven concentration points from $5 \mathrm{ng} / \mathrm{mL}$ to $150 \mathrm{ng} / \mathrm{mL}$ and from $0.78 \mathrm{ng} / \mathrm{mL}$ to $200 \mathrm{ng} / \mathrm{mL}$ was used for quantification for compounds of class $\mathrm{A}$ and $\mathrm{B}$, respectively. To quantify target compounds with concentrations beyond these limits, dilutions were performed on the sample prior to analysis until the concentration of the target compound was within the concentrations range of the calibration curve. The Limits of Detection (LODs) were determined based upon analysis of serial dilutions of standards of each target analyte. The limits of quantification (LOQs) were defined as 3.3xLODs. The LODs and LOQs for each target compound are listed in Table 1.

\subsection{Removal calculations}

The measured concentrations of CECs at the influent of each treatment unit, along with the load fractions were used to calculate a reference influent load, using Eq. 1. This reference load was compared to the effluent load of the treatment unit that is based on one day in order 
to obtain more reliable removal calculations, using the so-called fractionated approach (Eq. 2). Considering that samples from the effluent of each treatment unit were collected on multiple consecutive days, it was possible to calculate CEC removal values using different effluent loads as the basis for calculations. This is opposed to the commonly used day-by-day approach that calculates the removal by comparing input and output loads from the same day. In the present study, concentrations of CECs used for calculations of loads were based on the dissolved portion only of the CECs in the water phase.

Lref $=\sum_{i=1}^{i=n} f_{i * \operatorname{Linf}, i}$

$R=\frac{\text { Lref }- \text { Leff }}{\text { Lref }} * 100 \%$

- Lref: Reference mass load of the contaminant in the aqueous phase of the input stream $(\mathrm{mg} / \mathrm{d})$ based on several days of sampling (from the $i^{\text {th }}$ to the $n^{\text {th }}$ ). Where " $n$ " is the number of days of sampling.

- Linf, $i$ : Mass load of the contaminant in the input stream on the $\mathrm{i}^{\text {th }}$ day of sampling or "day i" (mg/d)

- $f_{i}$ : Load fraction or fraction of the incoming load on the $\mathrm{i}^{\text {th }}$ day of sampling (day $\mathrm{i}$ ) that is contained in the effluent load on the $\mathrm{n}^{\text {th }}$ day of sampling (day $\mathrm{n}$ )

- Leff : Mass load of the contaminant in the effluent on $\mathrm{n}^{\text {th }}$ day of sampling (mg/d)

- $R$ : Removal rate of contaminant based on the fractionated approach

\section{Results and Discussions}

\subsection{Hydraulic model}

\subsubsection{Calibration}

Conductivity and temperature were considered to be the conservative tracers defined within the WEST software. However, in reality, the measured conductivity of wastewater exhibited a reduction following the aeration tanks and a slight increase following primary and secondary clarification, as shown in Figure 1. As a result, it was necessary to rescale the predicted effluent conductivity to account for the actual decline or increase in this parameter observed within the WWTPs. This correction was necessary prior to evaluating the fit of the models, as it decreased the bias of the RMSE between predicted and measured conductivity due to the natural changes of the measured conductivity. The correction was based on the 
calculated percentage change of the average measured conductivity between the influent and the effluent of each treatment unit. The correction was assumed to be constant throughout the monitoring period. The effluent conductivity predicted by the model was multiplied by the observed percentage change to obtain a rescaled predicted conductivity. The best-fit models for WWTP A and WWTP B were determined based on the corrected predicted conductivity. The natural change of temperature through treatment units, on the other hand, was not significant and did not require correction.

\subsubsection{Model selection}

For WWTP A, the primary and secondary clarifiers were each modelled by a single clarifier, with a volume equivalent to the actual total volume. The 10-layered model of the clarifier assumes that the influent of the clarifier enters in the mid layer. Adjusting the feed layer to one layer below the mid layer and one layer above it for primary and secondary clarifiers respectively was shown to improve the fit of the hydraulic models. The model produced predictions of effluent conductivity that are in agreement with the observed conductivity, as illustrated in Figure 1(a) (dashed curves). With regards to the aeration tanks, increasing the number of aeration tanks in series to five tanks with the same actual total volume proved to improve the fit of the hydraulic model. Generally speaking, a model describing a WWTP with a large number of tanks in series exhibits a behaviour that approaches a "plug" flow (Levenspiel, 1972). WWTP A employs three-pass aeration tanks with a feed that enters the first pass, which is well represented by the semi-plug flow behaviour.

For WWTP B, the best-fit hydraulic model that minimizes the RMSE between predicted and observed temperature for the aeration tanks was observed to be a single aeration tank. Unlike aeration in WWTP A, step-feed operation is employed at the WWTP B. That is, the feed is entering at different points of the multi-pass aeration tanks, resulting in more homogeneous content in the aeration tank and making the system behave as a mixed tank. The effluent temperature profiles in Figure 1(b) show a wider residence time distribution (i.e. more broadening of the peaks) than profiles in Figure 1(a), suggesting that substantial mixing occurs in the activated sludge unit of WWTP B when compared to that of WWTP A. Similarly to WWTP A, the secondary clarifier was represented by a single clarifier with the actual total volume. 

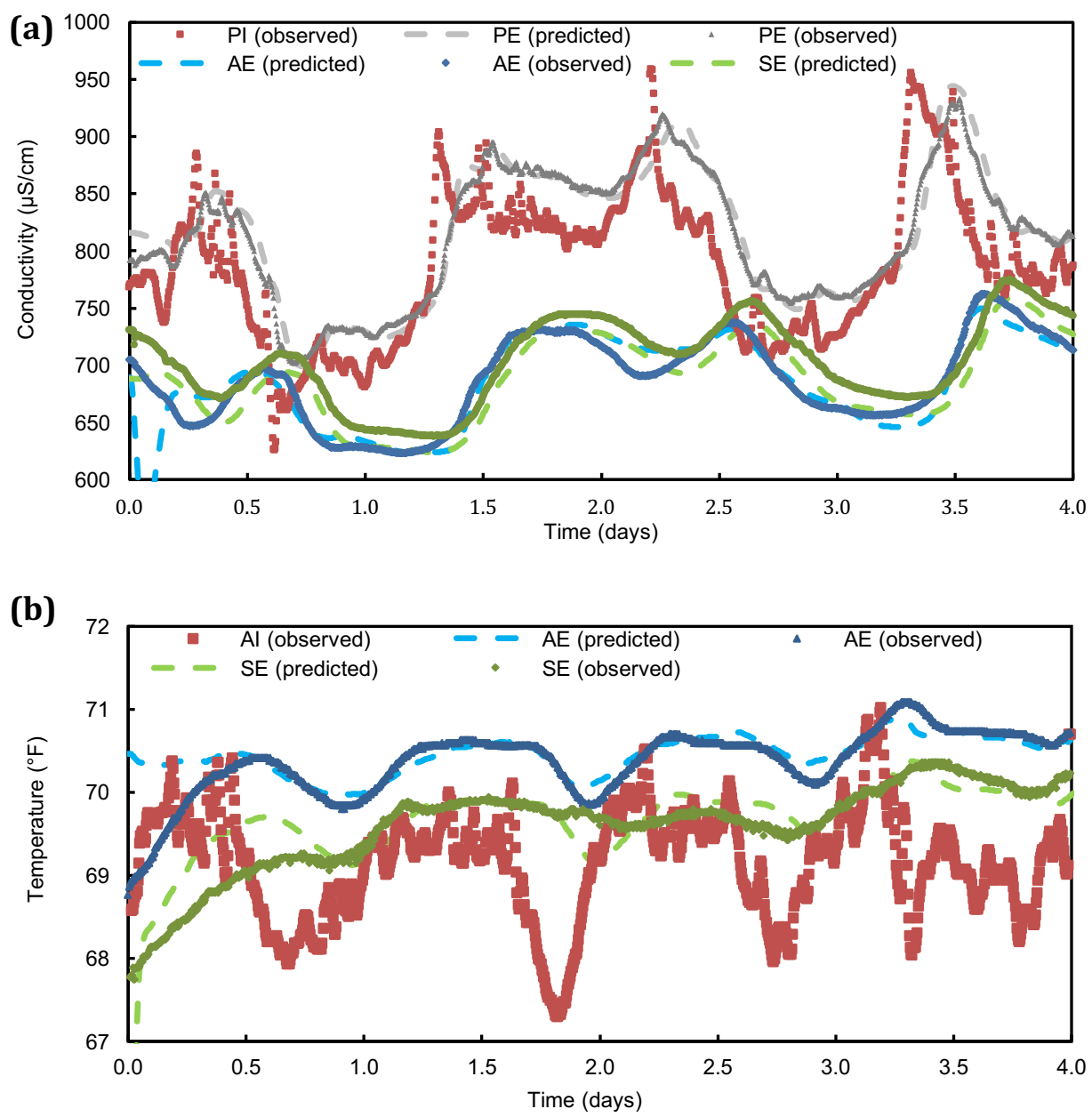

Figure 1. Observed (recorded) and predicted (simulated) conductivity trends in (a) WWTP A and (b) WWTP B at different locations (PI: influent to primary clarification, PE: effluent of primary clarification, AE: effluent of aeration, SE: effluent of secondary clarification)

\subsubsection{Load fractions}

Table 2 summarizes the load fractions determined for each treatment unit where, as previously explained, " $f_{i}$ " represents the load fractions that correspond tothe $4^{\text {th }}, 3^{\text {rd }}$ or $2^{\text {nd }}$ sampling day, depending on which day of the output was taken as a basis. It is important to note that the load fractions based on the effluent on a single day do not necessarily add up to $100 \%$, since each fraction is normalized against the influent load of a different sampling day (Eq. 1). As shown in Table 2, the effluent of the activated sludge unit of WWTP A on the last day of sampling (Day 3) contained influent material from the same and two previous days. This explains the need for three days of sampling at WWTP A to characterize the reference load that corresponds to the effluent load on the last day. The load fractions for the activated sludge unit of WWTP B were more widely distributed than those from WWTP A, as shown 
in Table 2, so four days of sampling were required. Figure 2 provides extra illustration of the response loads obtained from model simulations of the activated sludge treatment trains and used to calculate load fractions. Comparing the activated sludge unit to the primary clarifier, the load fractions obtained from the activated sludge are distributed over a larger number of days than the primary clarifier (i.e. three days), but with low contribution from the first sampling day of sampling (i.e. load fraction of $0.3 \%$ ). This is linked to the higher HRT and the greater extent of mixing that occurs in the activated sludge unit as compared to the primary clarifier. The load fractions were also evaluated for aeration tanks and secondary clarifier, separately. The secondary clarifier of WWTP A showed more distribution of load fractions over the days than that of WWTP B, while the opposite was observed for aeration tanks.

Table 2 Load fractions of influent loads composing the effluent on a given day for the different treatment units in WWTP A and WWTP B. "fi" denotes the fraction of influent load entering on day $i$ that is contained in effluent of day 4,3 or 2 (second column)

\begin{tabular}{|c|c|c|c|c|c|c|c|c|c|c|c|c|c|c|c|c|c|}
\hline \multirow[t]{2}{*}{ WWTP } & \multirow[t]{2}{*}{ Based on } & \multicolumn{4}{|c|}{$\begin{array}{l}\text { Load fractions of primary } \\
\text { clarifier }\end{array}$} & \multicolumn{4}{|c|}{$\begin{array}{l}\text { Load fractions of aeration } \\
\text { tanks }\end{array}$} & \multicolumn{4}{|c|}{$\begin{array}{l}\text { Load fractions of secondary } \\
\text { clarifier }\end{array}$} & \multicolumn{4}{|c|}{$\begin{array}{l}\text { Load fractions of activated } \\
\text { sludge }\end{array}$} \\
\hline & & f1 & f2 & f3 & $\mathrm{f4}$ & f1 & f2 & $\mathrm{f3}$ & $\mathrm{f} 4$ & $f 1$ & $\mathrm{f2}$ & f3 & $\mathrm{f} 4$ & f1 & f2 & f3 & f4 \\
\hline \multirow[t]{2}{*}{ WWTP A } & Day 3 effluent & 0.0 & 9.9 & 90.1 & - & 0.0 & 10.5 & 90.1 & - & 0.0 & 12.4 & 88.2 & - & 0.3 & 31.2 & 69.1 & - \\
\hline & Day 2 effluent & 10.2 & 90.1 & - & - & 10.6 & 89.5 & - & - & 9.7 & 90.0 & - & - & 32.9 & 68.5 & - & - \\
\hline \multirow[t]{2}{*}{ WWTP B } & Day 4 effluent & - & - & - & - & 0.0 & 1.0 & 28.4 & 70.7 & 0.0 & 0.0 & 3.1 & 97.3 & 0.5 & 4.8 & 38.8 & 55.0 \\
\hline & Day 3 effluent & - & - & - & - & 0.7 & 25.7 & 70.5 & - & 0.0 & 2.8 & 96.9 & - & 3.8 & 35.5 & 55.1 & - \\
\hline
\end{tabular}

The main factors causing the variations in load fractions between the different treatment units and the similar units between the two WWTPs (Table 2) are variations in volumes and flow rates, as well as the differences in the modes of operations. The different load fractions that are used to calculate the reference influent load (Eq. 1) eventually affect the calculation of the CEC removals (Eq. 2). Furthermore, due to the daily variation in the influent flow rates, as well as daily variations in the diurnal pattern of flow, slight daily variations are observed in the curves representing RTD of activated sludge on different days, as shown in Figure 2. 

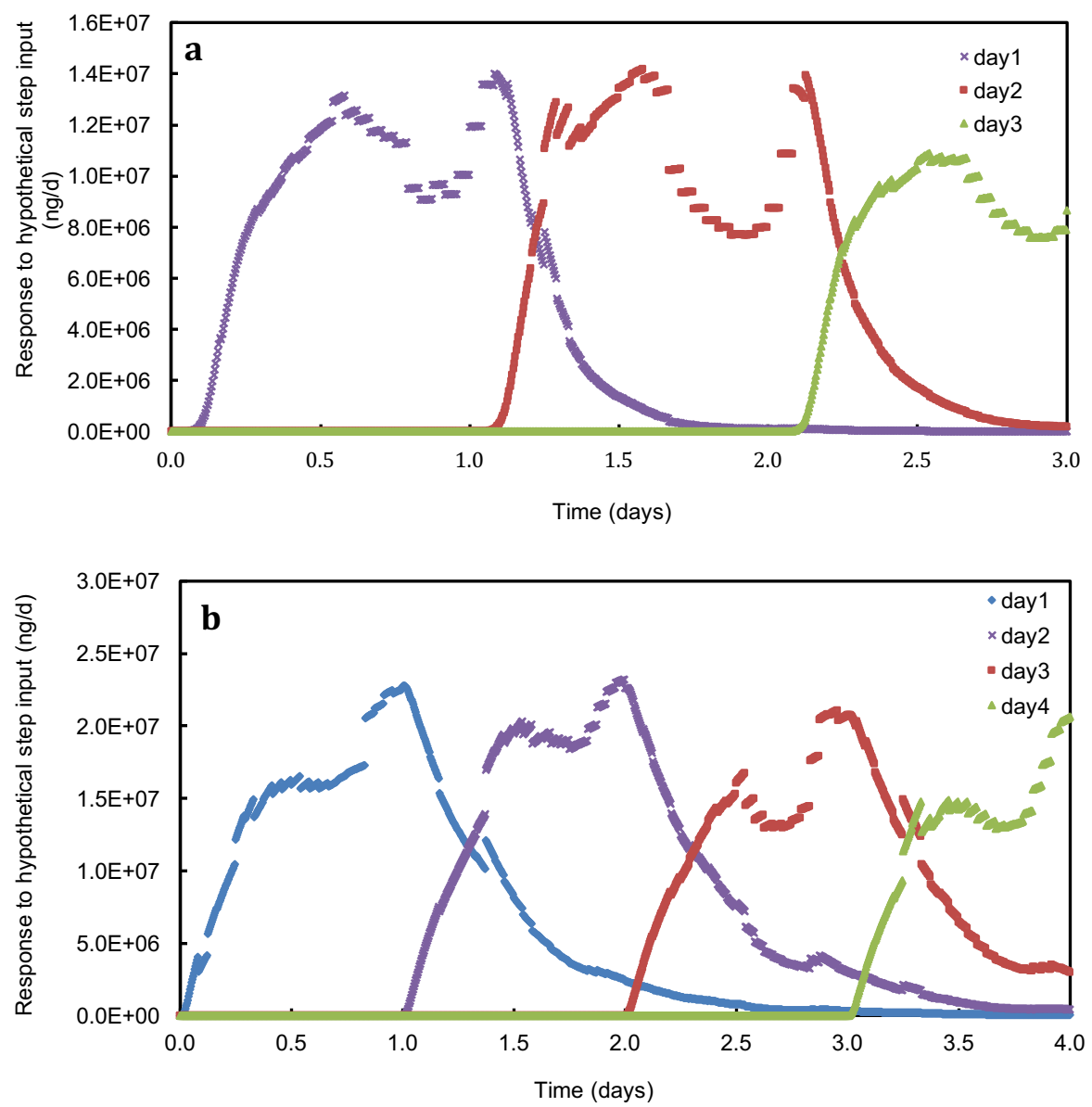

Figure 2. Simulated response to a hypothetical CEC 24-h step input: (a) Input applied on first, second and third days of sampling separately to the best-fit hydraulic model of the activated sludge unit in WWTP A; (b) Input applied on first, second, third and fourth sampling days separately to the best-fit hydraulic model of the activated sludge unit in WWTP B.

Therefore, as shown in Table 2, slightly different load fractions obtained for each treatment unit when different days are taken as the basis of the effluent load for removal calculation. Seasonal changes in flow rates would also be expected to have a significant effect on these calculations. This exercise illustrates the sensitivity of the fractionated approach to changes in the operating conditions within the WWTP. Eliminating this bias in CEC removal estimates by accounting for hydraulics is essential, especially when comparing the efficiency of different treatment stages or trains in removing CECs. The CEC removal efficiencies in primary and secondary treatment obtained by applying the fractionated approach are discussed in sections 3.3 and 3.4. 


\subsection{Concentrations of target contaminants}

The average measured concentrations and the calculated mass loads of CECs in the influent and effluent streams of both WWTPs are summarized in Table 3. In the influent streams of both WWTPs, the average concentrations of the target CECs ranged from $6 \mathrm{ng} / \mathrm{L}$ for estrone to $4,400 \mathrm{ng} / \mathrm{L}$ for sucralose at WWTP A and from $7 \mathrm{ng} / \mathrm{L}$ for estrone to $40,800 \mathrm{ng} / \mathrm{L}$ for caffeine at WWTP B. Trimethoprim was not detected in the influent of both WWTPs, while MDA and dihydrocodeine were not detected in the influent of WWTP A, but were detected in the influent of WWTP B. Codeine, morphine and sulfamethoxazole were not detected in the influent of WWTP B only (Table 3). Table 3 also presents the mass loads of the target CECs contained in the wastewater for each city. The differences in mass loads between the two cities might be explained by differences in the population characteristics and demographics influencing the patterns of use of these CECs. In general, no significant variations were observed for any of the CECs in the influent of WWTP A during the sampling period. The ratios of benzoylecgonine to cocaine concentrations were calculated to be 4.1 in WWTP A and 3.1 in WWTP B. According to Ratola et al. (2012), the majority of studies report a ratio of 3.1-3.5 in wastewater. It has been suggested that a ratio of benzoylecgonine to cocaine lower than 5 indicates that some cocaine was being discharged directly into the sewage without being consumed and metabolized (Karolak et al., 2010).

After the secondary treatment step in both WWTPs investigated, some compounds were $<$ LOD or $<\mathrm{LOQ}$, although they were detected in the influent, including sulfamethoxazole, cocaine and androstenedione for WWTP A and acetaminophen, ibuprofen, benzoylecgonine, amphetamine, MDA, dihydrocodeine, estrone and triclosan for WWTP B. The concentrations of sucralose were the highest of all target CECs in the effluent of both WWTPs, with average concentrations of around $5600 \mathrm{ng} / \mathrm{L}$ and $1100 \mathrm{ng} / \mathrm{L}$ in WWTP A and B, respectively. 
Table 3 Mean concentration ( $\mathrm{ng} / \mathrm{L} \pm \mathrm{SD}$ ) and mean mass loads (mg/d $\pm \mathrm{SD}$ ) of target CECs in the influent to the primary treatment and effluent of the secondary treatment at WWTP A and WWTP B. SD is standard deviation based on different days samples and their replicates ( $n=9$ for WWTP $A$ and $n=12$ for WWTP B)

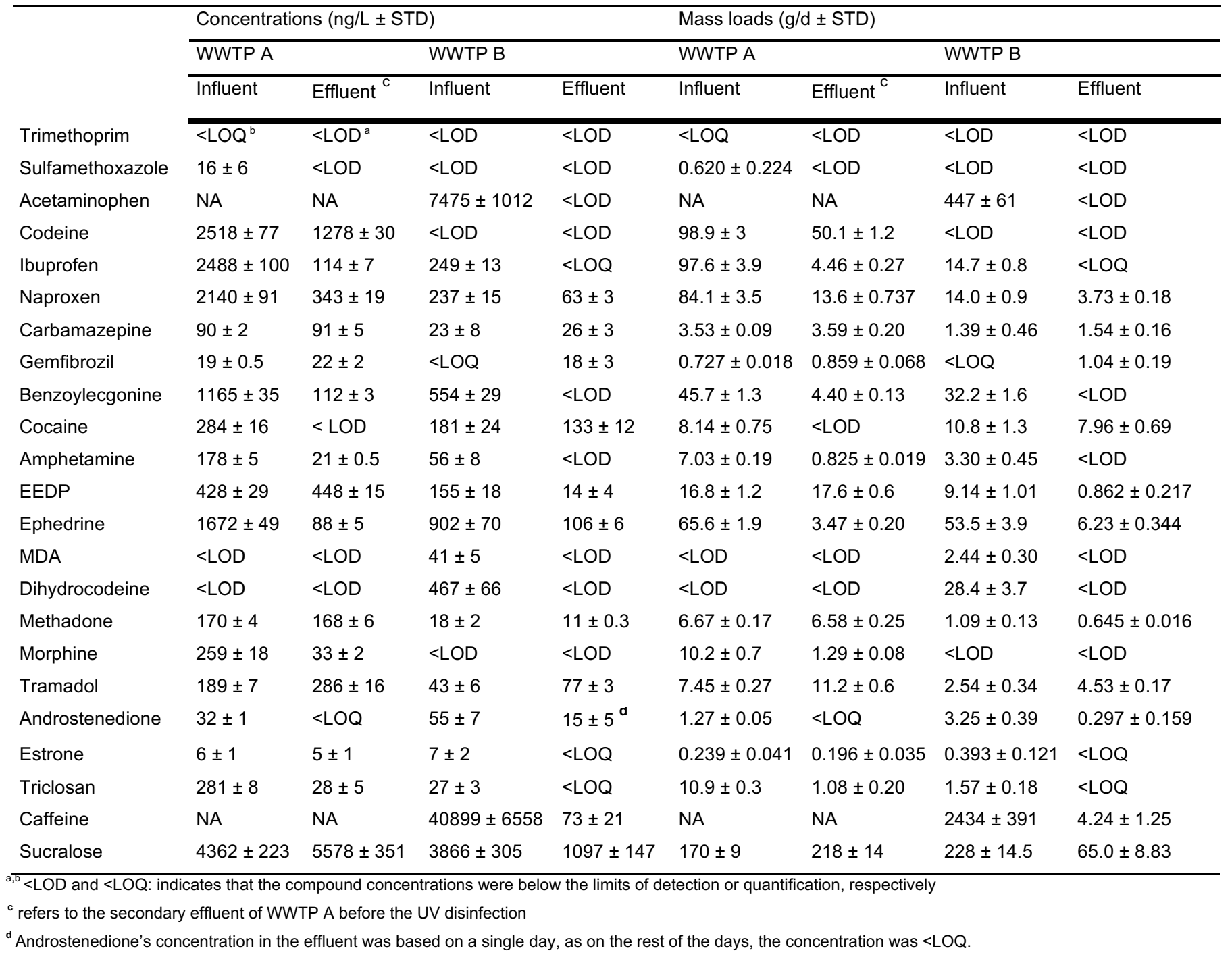

\subsection{Aqueous removal of CECs during primary clarification}

Removals of CECs during primary clarification were only determined for WWTP A, since WWTP B does not have a primary clarifier unit. The mass loads of the influent to the primary clarifier of WWTP A were calculated using the fractionated approach and using both day 2 and day 3 effluent as the basis of the calculation. Results for reference (influent) and effluent mass loads of all CECs are presented in Figure S1, and average removal efficiencies in the primary treatment process are summarized in Table 4. The reference mass loads were generally higher when based on day 2 effluent than when based on day 3 effluent, which can be explained by the higher concentrations of most CECs observed in the influent on the 
second day of sampling. On the other hand, the effluent mass loads observed on the second and the third days of sampling (day 2 and day 3 ) were comparable.

Triclosan was estimated to have the highest removal (94\%) in the primary clarifier, which is in agreement with previously reported results (Behera et al., 2011; Blair et al., 2013; Winkler et al., 2007). The high removals in the primary clarifier are likely due to the high $\log \mathrm{K}_{\mathrm{ow}}$ of this compound (i.e. 4.76), which contributes to partitioning to sludge during the primary treatment step (Rogers, 1996). In addition to adsorption, some biodegradation of CECs is expected to take place in the primary clarifier, contributing to their removal from the aqueous phase (Jones et al., 2005; Petrie et al., 2014). Androstenedione, carbamazepine, gemfibrozil, ibuprofen, naproxen and sucralose had poor removals of $10-20 \%$ in the primary clarifier. Poor removal of these compounds during primary clarification was also reported in previous studies (Behera et al., 2011; Blair et al., 2013; Ternes \& Joss, 2006; Zorita et al., 2009). It is notable that androstenedione, which is an intermediate in the biosynthesis of testosterone, was poorly removed by primary clarification. There are only limited monitoring data for this compound in the literature (Esperanza et al., 2007). In the case of ibuprofen and naproxen that have similar $\mathrm{pK}_{\mathrm{a}}(<4)$ and $\log \mathrm{K}_{\mathrm{ow}}$ values (3-4), their removals in the primary clarifier were almost equivalent at $13-15 \%$. Estrone, which is a metabolite of estradiol, showed negative removal in the primary clarifier. Negative removals of estrone during primary clarification have also been reported by others (Andersen et al., 2003; Behera et al., 2011; Carballa et al., 2004; Kirk et al., 2002; Ternes et al., 1999). These observations were attributed to the transformation of estradiol to estrone during primary clarification (Andersen et al., 2003; Carballa et al., 2004; Verlicchi et al., 2012).

Because of the anaerobic conditions and short residence times in the primary clarifier, biodegradation of CECs is likely low. Photolytic degradation is also expected to be low in the primary clarifier because of short residence times. Also, since the target compounds have low volatility, the removal of the target CECs in the primary clarifier is likely due to the sorption to primary sludge. Among the drugs of abuse monitored, the highest removal in the primary clarifier was $15 \%$ for tramadol, which can be explained by the relatively high hydrophobicity of tramadol compared to the other drugs of abuse monitored, resulting in a higher tendency to sorb to sludge (Table 1). Some target compounds, namely methadone, EDDP, ephedrine and 
cocaine showed negative removals in the primary clarifier, even using the fractionated approach. Subedi and Kannan (2014b) reported negative removals of methadone and its metabolite, EDDP during a primary treatment process, consistent with the observations in the present study. Since sorption and desorption are likely the primary processes affecting the CEC concentrations in the primary clarifier, it is possible that desorption of these compounds from particulate material in the raw wastewater into the aqueous phase takes place during primary clarification. The trends in the removal of drugs of abuse during primary clarification are in agreement with the limited literature available for these compounds (Rodayan et al., 2014a; Subedi \& Kannan, 2014b).

Overall, these results demonstrate that primary clarification has limited capacity for removing many of the target CECs, with 14 out of the 17 compounds showing removals $<20 \%$ during this step in the treatment train at WWTP A. This is consistent with these compounds being relatively hydrophilic and having a low tendency to partition onto solids due to their low $\log$ $\mathrm{K}_{\mathrm{ow}}(<3)$ and low $\mathrm{pK}_{\mathrm{a}}$.

It is important to emphasize that this study has focused on the CEC removal from the aqueous phase (i.e. removal of the dissolved proportion of the CEC) without accounting for the CEC load sorbed to particulate material. In fact, Miège et al. (2009) reported that only 15 of 117 peer-reviewed articles examining CEC fate in WWTPs measured the CEC concentrations in sludge and only one considered the CEC concentration in both aqueous and particulate phases for removal calculations. Some sorption of CECs onto filters is expected to take place during sample preparation. However, a previous study by Miao and Metcalfe (2007) evaluated the proportion of CECs sorbed to suspended particulates by analyzing the particulate material removed by centrifugation prior to SPE. This study concluded that the proportion of the CEC load retained on particulates is negligible compared to the amount dissolved in the wastewater for most water soluble CECs (Miao \& Metcalfe, 2007). Thus, the adsorption of CECs on filters that takes place during sample preparation introduces negligible bias to the calculation of removals during wastewater treatment.

\subsection{Aqueous removal of CECs during activated sludge treatment}

As with the primary clarifier, the matching mass loads of CECs in the aqueous phase of the influent and effluent of the activated sludge unit were calculated, as illustrated in Figure S2 
and Figure S3 for WWTP A and WWTP B, respectively. In WWTP A, the effluent mass loads used for calculating removals were based on both the second and third sampling days (as for the primary clarifier), while for WWTP B, it was based on the fourth and third sampling days. The average removals of target compounds in the activated sludge treatment step for the two WWTPs are also presented in Table 4.

The majority of the removals for most of the target compounds took place in the activated sludge step, when compared to the low removals in the primary clarifier of WWTP A (Table 4). Amphetamine and benzoylecgonine exhibited removals of $>90 \%$ during activated sludge treatment, consistent with previous research on the removal of these two compounds in WWTPs with activated sludge treatment (Bijlsma et al., 2012; Postigo et al., 2010; Rodayan et al., 2014a). Acetaminophen and caffeine were shown to undergo substantial removal (WWTP B) of almost 100\%, probably due to biodegradation, as suggested in previous studies (Behera et al., 2011; Kasprzyk-Hordern et al., 2009; Yang et al., 2011). Acetaminophen and caffeine were also shown to undergo substantial removal (WWTP B) of almost 100\%, which is in agreement with previous studies (Behera et al., 2011; Kasprzyk-Hordern et al., 2009; Yang et al., 2011). Removals of $92-95 \%$ and $72-77 \%$ were observed for ibuprofen and naproxen, respectively in the activated sludge process for both WWTPs, which is in good agreement with previous findings (Behera et al., 2011; Kasprzyk-Hordern et al., 2009; Sim et al., 2010; Yang et al., 2011). Removals of androstenedione were $>93 \%$ in WWTP A and 74\% in WWTP B. Almost complete removal of androstenedione from wastewater was previously reported by Esperanza et al. (2007).

Low removals of $<40 \%$ were observed for estrone and carbamazepine during the activated sludge treatment at both WWTPs, indicating that these compounds are persistent. These observations for carbamazepine are consistent with the many studies showing that carbamazepine is very persistent in WWTPs (Behera et al., 2011; Kasprzyk-Hordern et al., 2009; Miège et al., 2009; Yang et al., 2011). Estrone was previously reported to be persistent in some studies (Castiglioni et al., 2006; Zorita et al., 2009), although other studies reported high removal (Behera et al., 2011; Miège et al., 2009). The wide range of the CEC removal efficiencies reported in the literature illustrate the value of the fractionation method for generating reliable and consistent data on removals of CECs. 
Table 4 Removals (\%) of target compounds in primary clarifier and activated sludge treatment steps in WWTP B and WWTP A

\begin{tabular}{|c|c|c|c|}
\hline Compound & $\begin{array}{l}\text { Removal in primary } \\
\text { clarifier (\%) }\end{array}$ & $\begin{array}{l}\text { Removal in } \\
\text { Activated sludge (\%) }\end{array}$ & \\
\hline & WWTP A & WWTP A & WWTP B \\
\hline Trimethoprim & $<\mathrm{LOD}^{\mathrm{a}}$ & $<L^{\prime} O Q^{b}$ & $<\mathrm{LOD}^{\mathrm{a}}$ \\
\hline Sulfamethoxazole & $16^{\mathrm{c}}$ & $71^{\mathrm{c}}$ & $<\mathrm{LOD}^{\mathrm{a}}$ \\
\hline Acetaminophen & $N A^{d}$ & $N A^{d}$ & 100 \\
\hline Codeine & 1 & 54 & $<\mathrm{LOD}^{\mathrm{a}}$ \\
\hline Ibuprofen & 15 & 95 & 92 \\
\hline Naproxen & 14 & 77 & 72 \\
\hline Carbamazepine & 13 & 15 & 7 \\
\hline Gemfibrozil & 20 & -39 & -37 \\
\hline Benzoylecgonine (cocaine metabolite) & 3 & 90 & 99 \\
\hline Cocaine & -4 & $77^{\mathrm{c}}$ & 42 \\
\hline Amphetamine & 6 & $91^{\mathrm{c}}$ & $90^{\mathrm{c}}$ \\
\hline EEDP (methadone's metabolite) & -8 & 32 & 93 \\
\hline Ephedrine & -2 & 95 & 88 \\
\hline MDA & $<\mathrm{LOD}^{\mathrm{a}}$ & $<\mathrm{LOD}^{\mathrm{a}}$ & $75^{c}$ \\
\hline Dihydrocodeine & $<\mathrm{LOD}^{\mathrm{a}}$ & $<\mathrm{LOD}^{\mathrm{a}}$ & $95^{c}$ \\
\hline Methadone & -20 & 25 & 44 \\
\hline Morphine (codeine metabolite) & 3 & 91 & $<\mathrm{LOD}^{\mathrm{a}}$ \\
\hline Tramadol & 15 & -47 & -73 \\
\hline Triclosan & 94 & 61 & $38^{\mathrm{c}}$ \\
\hline Androstenedione & 11 & $93^{c}$ & 74 \\
\hline Estrone & -31 & 34 & $24^{\mathrm{c}}$ \\
\hline Caffeine & $N A^{d}$ & $N A^{d}$ & 100 \\
\hline Sucralose & 20 & -50 & 68 \\
\hline
\end{tabular}

$\overline{a, b}<$ LOD and $<$ LOQ: indicates that the compound concentrations were below the LOD or LOQ in both the influent and effluent and that removals could not be calculated.

${ }^{c}$ Denotes that the compound concentrations were either $\angle L O Q$ or $\angle L O D$ in the effluent of the corresponding treatment stage and that removal was calculated assuming a concentration equal to LOQ \& LOD, respectively, indicating that the removal might actually be higher than the reported values.

${ }^{d} \mathrm{NA}$ : indicates compounds that were not analyzed, such as acetaminophen and caffeine that were later added to the list of target CECs and were not quantified in the samples from WWTP A.

Negative removals were observed for tramadol and gemfibrozil in the activated sludge step of both WWTPs under study, which may be due to the presence of conjugated metabolites in the influent of the unit that are converted to the parent compound by the activated sludge treatment, as was suggested by other authors (Jelic et al., 2011; Lishman et al., 2006). There was also negative removal of the artificial sweetener, sucralose, in the activated sludge unit at WWTP A, while a positive removal of $68 \%$ was calculated for this compound in WWTP B. Among the limited studies on the fate of sucralose in WWTPs, low removals of sucralose in 
activated sludge were previously reported (Pasquini et al., 2013; Subedi \& Kannan, 2014a), and a number of negative removals of sucralose were observed in Norwegian and Swedish WWTPs (Brorström-Lunden, 2008; Green, 2007). These were linked to the possibility of the presence of conjugated and complex forms of sucralose in the influent load, which might transform back to the parent form during the biological treatment. Negative and variable removals of carbamazepine were obtained in WWTP A and WWTP B using the day-by-day approach of removal calculation (results not shown here); however, the fractionated approach yielded positive and consistent removals.

\section{Conclusions}

In order to obtain reliable data on the removals of CECs during treatment of wastewater, it is essential to account for mixing regimes that affect the transport of CECs in the WWTP. In this study, we applied the fractionated approach to characterize CEC removals in two WWTPs. Based on the hydraulic modelling using the fractionated approach, WWTP B had a longer HRT, as well as a higher degree of mixing than the activated sludge unit in WWTP A, resulting in the need for data over more sampling days for reliable quantification of removal in WWTP B, as well as different calculations of CEC removal. The removals of target CECs were generally low or negative in the primary clarifier and ranged from negative removals to $100 \%$ removal over the entire activated sludge treatment train. This study contributes to advancing the study of the fractionation approach by applying this approach to the primary treatment step and demonstrating that the method is able to detect differences in the hydrodynamics of each of the units investigated at the two treatment plants, resulting in different removal calculations for each unit. Further, the removals estimated for an extended list of target CECs obtained in this study by taking into account hydrodynamics are key for calibrating fate models for CECs. These models can be used to improve our understanding of CEC fate during wastewater treatment and to provide insights for limiting the discharge of contaminants into surface waters.

Acknowledgements: The authors thank the staff at the two WWTPs for help during the sampling campaigns. We gratefully acknowledge the McGill Engineering doctoral award for supporting Zeina Baalbaki. We also thank Brenda McIlwain for preparing samples for analysis at Trent University, and Craig Murray for his help in deploying 
temperature/conductivity probes at WWTP A. Funding for this study was provided by a research grant to Viviane Yargeau (PI) and colleagues from the Natural Sciences and Engineering Research Council (NSERC) of Canada through the Strategic Grants Program (430646-2012). 


\section{References:}

Ahnert, M., Kuehn, V., \& Krebs, P. 2010. Temperature as an alternative tracer for the determination of the mixing characteristics in wastewater treatment plants. Water Research. 44, 1765-1776. doi: http://dx.doi.org/10.1016/j.watres.2009.11.047

Andersen, H., Siegrist, H., Halling-Sørensen, B., \& Ternes, T. A. 2003. Fate of estrogens in a municipal sewage treatment plant. Environmental Science \& Technology. 37, 4021-4026. doi: http://dx.doi.org/10.1021/es026192a

Behera, S. K., Kim, H. W., Oh, J.-E., \& Park, H.-S. 2011. Occurrence and removal of antibiotics, hormones and several other pharmaceuticals in wastewater treatment plants of the largest industrial city of Korea. Science of The Total Environment. 409, 4351-4360. doi: http://dx.doi.org/10.1016/j.scitotenv.2011.07.015

Bijlsma, L., Emke, E., Hernández, F., \& de Voogt, P. 2012. Investigation of drugs of abuse and relevant metabolites in Dutch sewage water by liquid chromatography coupled to high resolution mass spectrometry. Chemosphere. 89, 1399-1406. doi: http://dx.doi.org/10.1016/j.chemosphere.2012.05.110

Blair, B. D., Crago, J. P., Hedman, C. J., Treguer, R. J. F., Magruder, C., Royer, L. S., \& Klaper, R. D. 2013. Evaluation of a model for the removal of pharmaceuticals, personal care products, and hormones from wastewater. Science of The Total Environment. 444, 515-521. doi: http://dx.doi.org/10.1016/j.scitotenv.2012.11.103

Brorström-Lunden, E., Svenson, A., Viktor, T., Woldegiorgis, A., Remberger, M., Kaj, L., Dye, C., Bjerke, A., Schlabach, M. (2008). Measurements of sucralose in the Swedish screening program 2007, PART I. Stockholm, Sweden: Swedish Environmental Research Institute Ltd.

Carballa, M., Omil, F., Lema, J. M., Llompart, M. a., García-Jares, C., Rodríguez, I., Gómez, M., \& Ternes, T. 2004. Behavior of pharmaceuticals, cosmetics and hormones in a sewage treatment plant. Water Research. 38, 2918-2926. doi: http://dx.doi.org/10.1016/j.watres.2004.03.029

Castiglioni, S., Bagnati, R., Fanelli, R., Pomati, F., Calamari, D., \& Zuccato, E. 2006. Removal of pharmaceuticals in sewage treatment plants in Italy. Environmental Science \& Technology. 40, 357-363. doi: http://dx.doi.org/10.1021/es050991m

Clara, M., Kreuzinger, N., Strenn, B., Gans, O., \& Kroiss, H. 2005. The solids retention time-a suitable design parameter to evaluate the capacity of wastewater treatment plants to remove micropollutants. Water Research. 39, 97-106. doi: http://dx.doi.org/10.1016/j.watres.2004.08.036

Dickenson, E. R. V., Snyder, S. A., Sedlak, D. L., \& Drewes, J. E. 2011. Indicator compounds for assessment of wastewater effluent contributions to flow and water quality. Water Research. 45, 1199-1212. doi: http://dx.doi.org/10.1016/j.watres.2010.11.012

Esperanza, M., Suidan, M. T., Marfil-Vega, R., Gonzalez, C., Sorial, G. A., McCauley, P., \& Brenner, R. 2007. Fate of sex hormones in two pilot-scale municipal wastewater treatment plants: Conventional treatment. Chemosphere. 66, 1535-1544. doi: http://dx.doi.org/10.1016/j.chemosphere.2006.08.020

Gay, F., Ferrandino, I., Monaco, A., Cerulo, M., Capasso, G., \& Capaldo, A. 2016. Histological and hormonal changes in the European eel (Anguilla anguilla) after 
exposure to environmental cocaine concentration. Journal of Fish Diseases. 39, 295-308. doi: http://dx.doi.org/10.1111/jfd.12362

Green, N., Schlabach, M., Bakke, T., Brevik, E.M., Dye, C., Herzke, D., Huber, S., Plosz, B., Remberger,M., Schøyen, M., Uggerud, H., T., Vogelsang, C. (2007). Screening of selected metals and new organic contaminants. Norway: Norwegian Pollution Control Authority.

Jelic, A., Gros, M., Ginebreda, A., Cespedes-Sánchez, R., Ventura, F., Petrovic, M., \& Barcelo, D. 2011. Occurrence, partition and removal of pharmaceuticals in sewage water and sludge during wastewater treatment. Water Research. 45, 1165-1176. doi: http://dx.doi.org/10.1016/j.watres.2010.11.010

Jones, 0. A. H., Voulvoulis, N., \& Lester, J. N. 2005. Human pharmaceuticals in wastewater treatment processes. Critical Reviews in Environmental Science and Technology. 35, 401-427. doi: http://dx.doi.org/10.1080/10643380590956966

Karolak, S., Nefau, T., Bailly, E., Solgadi, A., \& Levi, Y. 2010. Estimation of illicit drugs consumption by wastewater analysis in Paris area (France). Forensic Science International. 200, 153-160. doi: http://dx.doi.org/10.1016/j.forsciint.2010.04.007

Kasprzyk-Hordern, B., Dinsdale, R. M., \& Guwy, A. J. 2009. The removal of pharmaceuticals, personal care products, endocrine disruptors and illicit drugs during wastewater treatment and its impact on the quality of receiving waters. Water Research. 43, 363-380. doi: http://dx.doi.org/10.1016/j.watres.2008.10.047

Kidd, K. A., Blanchfield, P. J., Mills, K. H., Palace, V. P., Evans, R. E., Lazorchak, J. M., \& Flick, R. W. 2007. Collapse of a fish population after exposure to a synthetic estrogen. Proceedings of the National Academy of Sciences of the United States of America. 104, 8897-8901. doi: http://dx.doi.org/10.1073/pnas.0609568104

Kirk, L., Tyler, C., Lye, C., \& Sumpter, J. 2002. Changes in estrogenic and androgenic activities at different stages of treatment in wastewater treatment works. Environmental Toxicology and Chemistry. 21, 972-979. doi: http://dx.doi.org/10.1002/etc.5620210511

Kleywegt, S., Pileggi, V., Yang, P., Hao, C., Zhao, X., Rocks, C., Thach, S., Cheung, P., \& Whitehead, B. 2011. Pharmaceuticals, hormones and bisphenol A in untreated source and finished drinking water in Ontario, Canada - Occurrence and treatment efficiency. Science of The Total Environment. 409, 1481-1488. doi: http://dx.doi.org/10.1016/j.scitotenv.2011.01.010

Levenspiel, 0. (1972). Chemical Reaction Engineering (First Edition ed.). John Wiley and Sons, New York

Li, H., Helm, P. A., \& Metcalfe, C. D. 2010. Sampling in the Great Lakes for pharmaceuticals, personal care products, and endocrine-disrupting substances using the passive polar organic chemical integrative sampler. Environmental Toxicology and Chemistry. 29, 751-762. doi: http://dx.doi.org/10.1002/etc.104

Lishman, L., Smyth, S. A., Sarafin, K., Kleywegt, S., Toito, J., Peart, T., Lee, B., Servos, M., Beland, M., \& Seto, P. 2006. Occurrence and reductions of pharmaceuticals and personal care products and estrogens by municipal wastewater treatment plants in Ontario, Canada. Science of The Total Environment. 367, 544-558. doi: http://dx.doi.org/10.1016/j.scitotenv.2006.03.021 
Luo, Y., Guo, W., Ngo, H. H., Nghiem, L. D., Hai, F. I., Zhang, J., Liang, S., \& Wang, X. C. 2014. A review on the occurrence of micropollutants in the aquatic environment and their fate and removal during wastewater treatment. Science of the Total Environment. 473-474, 619-641.

doi: http://dx.doi.org/10.1016/j.scitotenv.2013.12.065

Majewsky, M., Farlin, J., Bayerle, M., \& Galle, T. 2013. A case-study on the accuracy of mass balances for xenobiotics in full-scale wastewater treatment plants. Environmental Science: Processes \& Impacts. 15, 730-738. doi: http://dx.doi.org/10.1039/C3EM30884G

Majewsky, M., Galle, T., Bayerle, M., Goel, R., Fischer, K., \& Vanrolleghem, P. A. 2011. Xenobiotic removal efficiencies in wastewater treatment plants: residence time distributions as a guiding principle for sampling strategies. Water Research. 45, 6152-6162. doi: http://dx.doi.org/10.1016/j.watres.2011.09.005

Mawhinney, D. B., Young, R. B., Vanderford, B. J., Borch, T., \& Snyder, S. A. 2011. Artificial sweetener sucralose in U.S. drinking water systems. Environmental Science and Technology. 45, 8716-8722. doi: http://dx.doi.org/10.1021/es202404c

Metcalfe, C., Hoque, M. E., Sultana, T., Murray, C., Helm, P., \& Kleywegt, S. 2014. Monitoring for contaminants of emerging concern in drinking water using POCIS passive samplers. Environmental Science: Processes \& Impacts. 16, 473-481. doi: http://dx.doi.org/10.1039/C3EM00508A

Metcalfe, C., Tindale, K., Li, H., Rodayan, A., \& Yargeau, V. 2010. Illicit drugs in Canadian municipal wastewater and estimates of community drug use. Environmental Pollution. 158, 3179-3185. doi: http://dx.doi.org/10.1016/i.envpol.2010.07.002

Miao, X.-S., \& Metcalfe, C. D. (2007). Analysis of neutral and acidic pharmaceuticals by liquid chromatography mass spectrometry (LC-MS, LC-MS/MS). In M. Petrovic \& D. Barcelo (Eds.), Analysis, Fate and Removal of Pharmaceuticals in the Water Cycle (Vol. 50, pp. 135-158). Amsterdam; London Elsevier.

Miège, C., Choubert, J. M., Ribeiro, L., Eusèbe, M., \& Coquery, M. 2009. Fate of pharmaceuticals and personal care products in wastewater treatment plants Conception of a database and first results. Environmental Pollution. 157, 17211726. doi: http://dx.doi.org/10.1016/j.envpol.2008.11.045

National Center for Biotechnology Information. (2004). PubChem Compound Database. Available from National Center for Biotechnology Information, U.S. National Library of Medicine PubChem Compound Retrieved 1/8/2016 https://pubchem.ncbi.nlm.nih.gov

Onesios, K. M., Yu, J. T., \& Bouwer, E. J. 2009. Biodegradation and removal of pharmaceuticals and personal care products in treatment systems: a review. Biodegradation. 20, 441-466. doi: http://dx.doi.org/10.1007/s10532-008-9237$\underline{8}$

Ort, C., Lawrence, M. G., Rieckermann, J., \& Joss, A. 2010. Sampling for pharmaceuticals and personal care products (PPCPs) and illicit drugs in wastewater systems: Are your conclusions valid? A critical review. Environmental Science and Technology. 44, 6024-6035. doi: http://dx.doi.org/10.1021/es100779n

Pasquini, L., Munoz, J.-F., Rimlinger, N., Dauchy, X., France, X., Pons, M.-N., \& Görner, T. 2013. Assessment of the fate of some household micropollutants in urban wastewater treatment plant. Chemical Papers. 67, 601-612. doi: http://dx.doi.org/10.2478/s11696-013-0339-3 
Petrie, B., McAdam, E. J., Lester, J. N., \& Cartmell, E. 2014. Obtaining process mass balances of pharmaceuticals and triclosan to determine their fate during wastewater treatment. Science of The Total Environment. 497-498, 553-560. doi: http://dx.doi.org/10.1016/j.scitotenv.2014.08.003

Postigo, C., López de Alda, M. J., \& Barceló, D. 2010. Drugs of abuse and their metabolites in the Ebro River basin: Occurrence in sewage and surface water, sewage treatment plants removal efficiency, and collective drug usage estimation. Environment International. 36, 75-84. doi: http://dx.doi.org/10.1016/j.envint.2009.10.004

Purdom, C. E., Hardiman, P. A., Bye, V. V. J., Eno, N. C., Tyler, C. R., \& Sumpter, J. P. 1994. Estrogenic effects of effluents from sewage treatment works. Chemistry and Ecology. 8, 275-285. doi: http://dx.doi.org/10.1080/02757549408038554

Ratola, N., Cincinelli, A., Alves, A., \& Katsoyiannis, A. 2012. Occurrence of organic microcontaminants in the wastewater treatment process. A mini review. Journal of Hazardous Materials. 239-240, 1-18. doi: http://dx.doi.org/10.1016/j.jhazmat.2012.05.040

Rodayan, A., Afana, S., Segura, P. A., Sultana, T., Metcalfe, C. D., \& Yargeau, V. 2015. Linking drugs of abuse in wastewater to contamination of surface and drinking water. Environmental Toxicology and Chemistry. 35, 843-849. doi: http://dx.doi.org/10.1002/etc.3085

Rodayan, A., Majewsky, M., \& Yargeau, V. 2014a. Impact of approach used to determine removal levels of drugs of abuse during wastewater treatment. Science of The Total Environment. 487, 731-739. doi: http://dx.doi.org/10.1016/j.scitotenv.2014.03.080

Rodayan, A., Segura, P. A., \& Yargeau, V. 2014b. Ozonation of wastewater: Removal and transformation products of drugs of abuse. Science of The Total Environment. 487, 763-770. doi: http://dx.doi.org/10.1016/j.scitotenv.2013.11.023

Rogers, H. R. 1996. Sources, behaviour and fate of organic contaminants during sewage treatment and in sewage sludges. Science of The Total Environment. 185, 3-26. doi: http://dx.doi.org/10.1016/0048-9697(96)05039-5

Schwab, B. W., Hayes, E. P., Fiori, J. M., Mastrocco, F. J., Roden, N. M., Cragin, D., Meyerhoff, R. D., D’Aco, V. J., \& Anderson, P. D. 2005. Human pharmaceuticals in US surface waters: A human health risk assessment. Regulatory Toxicology and Pharmacology. 42, 296-312. doi: http://dx.doi.org/10.1016/j.yrtph.2005.05.005

Sim, W.-J., Lee, J.-W., \& Oh, J.-E. 2010. Occurrence and fate of pharmaceuticals in wastewater treatment plants and rivers in Korea. Environmental Pollution. 158, 1938-1947. doi: http://dx.doi.org/10.1016/j.envpol.2009.10.036

Subedi, B., \& Kannan, K. 2014a. Fate of artificial sweeteners in wastewater treatment plants in New York State, U.S.A. Environmental Science \& Technology. 48, 1366813674. doi: http://dx.doi.org/10.1021/es504769c

Subedi, B., \& Kannan, K. 2014b. Mass loading and removal of select illicit drugs in two wastewater treatment plants in New York State and estimation of illicit drug usage in communities through wastewater analysis. Environmental Science \& Technology. 48, 6661-6670. doi: http://dx.doi.org/10.1021/es501709a

Ternes, T. A. 1998. Occurrence of drugs in German sewage treatment plants and rivers1. Water Research. 32, 3245-3260. doi: http://dx.doi.org/10.1016/S0043$\underline{1354(98) 00099-2}$ 
Ternes, T. A., \& Joss, A. (2006). Human Pharmaceuticals, Hormones and Fragrances: The Challenge of Micropollutants in Urban Water Management. IWA Publishing, London, UK

Ternes, T. A., Stumpf, M., Mueller, J., Haberer, K., Wilken, R. D., \& Servos, M. 1999. Behavior and occurrence of estrogens in municipal sewage treatment plants - I. Investigations in Germany, Canada and Brazil. Science of The Total Environment. 225, 81-90. doi: http://dx.doi.org/10.1016/S0048-9697(98)00334-9

U.S. National Library of Medicine. (2005). ChemIDPLUS. Available from U.S. National library of Medicine TOXNET http://toxnet.nlm.nih.gov

Verlicchi, P., Al Aukidy, M., \& Zambello, E. 2012. Occurrence of pharmaceutical compounds in urban wastewater: removal, mass load and environmental risk after a secondary treatment--a review. Science of the Total Environment. 429, 123-155. doi: http://dx.doi.org/10.1016/j.scitotenv.2012.04.028

Webb, S., Ternes, T., Gibert, M., \& Olejniczak, K. 2003. Indirect human exposure to pharmaceuticals via drinking water. Toxicology Letters. 142, 157-167. doi: http://dx.doi.org/10.1016/S0378-4274(03)00071-7

Winkler, G., Thompson, A., Fischer, R., Krebs, P., Griffin, P., \& Cartmell, E. 2007. Mass flow balances of triclosan in small rural wastewater Tteatment plants and the impact of biomass parameters on the removal. Engineering in Life Sciences. 7, 42-51. doi: http://dx.doi.org/10.1002/elsc.200620158

Yang, X., Flowers, R. C., Weinberg, H. S., \& Singer, P. C. 2011. Occurrence and removal of pharmaceuticals and personal care products (PPCPs) in an advanced wastewater reclamation plant. Water Research. 45, 5218-5228. doi: http://dx.doi.org/10.1016/j.watres.2011.07.026

Yargeau, V., Rodayan, A., Taylor, B., Li, H., \& Metcalfe, C. D. 2014. Analysis of drugs of abuse in wastewater from two Canadian cities. Science of The Total Environment. 487, 722-730. doi: http://dx.doi.org/10.1016/j.scitotenv.2013.11.094

Zorita, S., Mårtensson, L., \& Mathiasson, L. 2009. Occurrence and removal of pharmaceuticals in a municipal sewage treatment system in the south of Sweden. Science of The Total Environment. 407, 2760-2770. doi: http://dx.doi.org/10.1016/j.scitotenv.2008.12.030 